\title{
Research on Docking of Supply and Demand of Rural Informationization and "Internet Digital Divide" in Urban and Rural Areas in China
}

\author{
Zhongwei Sun ${ }^{1}$, Yang Wang ${ }^{2, *}$, and Peng $\mathrm{Lu}^{2}$ \\ ${ }^{1}$ Department of Resource \& Environment, Shijiazhuang College, 050035 Shijiazhuang, China \\ ${ }^{2}$ Institute for Tourism Studies, Hebei Normal University, 050031 Shijiazhuang, China \\ wangyang209@126. com
}

\begin{abstract}
Based on the cognition of "internet digital divide" from five respects in urban and rural areas in China, the paper analyzes the key links of relieving the question of "internet digital divide" in urban and rural areas and the construction of rural informationization. The research discovers that improving the human quality is the most important factor in solving the problem of the rural areas residents to contact network, and increasing the farmers' income is the key to raise internet popularity rate of the rural areas, and the mobile phone and construction of information service centre of various forms are important ways for the rural areas residents to contact network. This paper also proposes that the key point of the following work of rural informationization in China is to realize the docking of supply and demand through enhancing government information supplies and increasing information demands of rural areas.
\end{abstract}

Keywords: Urban and rural areas, Internet digital divide, Rural informationization, Docking of supply and demand, China.

\section{Introduction}

The rural areas informationization refers to construct the information service system to promote communication and knowledge sharing through strengthening the information infrastructure constructions in rural areas, broadcasting television network, telecommunication network, computer network and so on and to fully develop and use information resource, in order to realize the popularization application degree and process of the modern information technology in each aspect of the rural areas production circulation, the management and operation, the culture and education, the social management and the public service and so on (Li,2009). The internet construction and its application is the important contents of rural areas informationization in China, simultaneously it is also the most economical and convenient way to promote the informationization of the rural areas.

\footnotetext{
* Corresponding author.
} 


\section{The Present Situation of "Internet Digital Divide" in Chinese Urban and Rural Areas}

\subsection{Netizens' Dimensions and Popularity Rate in the Urban and Rural Areas}

The difference of netizen dimensions and the popularity rate in urban and rural areas is one of the two major problems of internet digital divide. Up to the end of 2009, the population number in Chinese cities is $621,860,000$, in which netizen dimensions is $277,190,000$, the cities netizen popularity rate is $44.6 \%$, the inhabitant population in rural areas is $712,880,000$, in which netizen population is $106,810,000$, the countryside netizen popularity rate is $15.0 \%$.At present, the countryside netizen population in China occupies $27.8 \%$ in the total quantity of netizens.Although the speed-up of countryside netizens was very quick in recent years, but the rural areas netizen popularity rate was still far lower than the national average level, also is enlarged gradually with the cities netizen popularity rate disparity (to see Tab.1).In addition, the internet popularity rates of east, middle and west of China at the end of 2007 are $14.4 \%, 4.4 \%$ and $3.5 \%$, this explains the internet digital divide question among different regional rural areas is also serious.

Table 1. Netizens' popularity rate in China from 2005 to 2009

\begin{tabular}{lccccc}
\hline Names of index & 2005 & 2006 & 2007 & 2008 & 2009 \\
\hline Netizen popularity rate in urban and town (\%) & 16.9 & 20.2 & 27.3 & 35.2 & 44.6 \\
Netizen popularity rate in China (\%) & 8.5 & 10.5 & 16.0 & 22.6 & 28.9 \\
Netizen popularity rate in rural areas (\%) & 2.6 & 3.1 & 7.1 & 11.7 & 15.0 \\
\hline
\end{tabular}

\subsection{Net Touching Place and Way of Netizens in Urban and Rural Areas}

The net touching place and way of netizen in Chinese urban and rural areas are different greatly (to see Figure 1). Firstly, the family and the internet bar are the most main places in which netizens access the net, but the choice of accessing the net by netizens from urban and rural areas are somewhat different. The proportion of family surfer crowds from rural areas is $68.0 \%$, which is lower than the cities of $14.3 \%$.But the proportion of internet bar netizen from rural areas is $54.2 \%$, which is higher than the cities of $16.2 \%$.Among 84,600,000 countryside netizens at the end of 2008, the population of internet bar netizen achieves $45,850,000$, in which the population of the internet bar surfer netizen is only approximately 7,870,000.Secondly, the net touching way of netizens in Chinese urban and rural areas exists difference. The desktop computer is still the main equipment which the netizen accesses the net, the difference between town and county is not obvious, simultaneously the cities' netizen proportion who uses the portable computer surfer is $10.9 \%$ higher than that of the rural areas. Up to the end of 2008, the handset surfer users in Chinese cities are 77,890,000, it occupies $36.5 \%$ over all cities netizen; the handset surfer users in Chinese rural areass are approximately $40,100,000$, and it occupies $47.4 \%$ of all countryside netizens. 


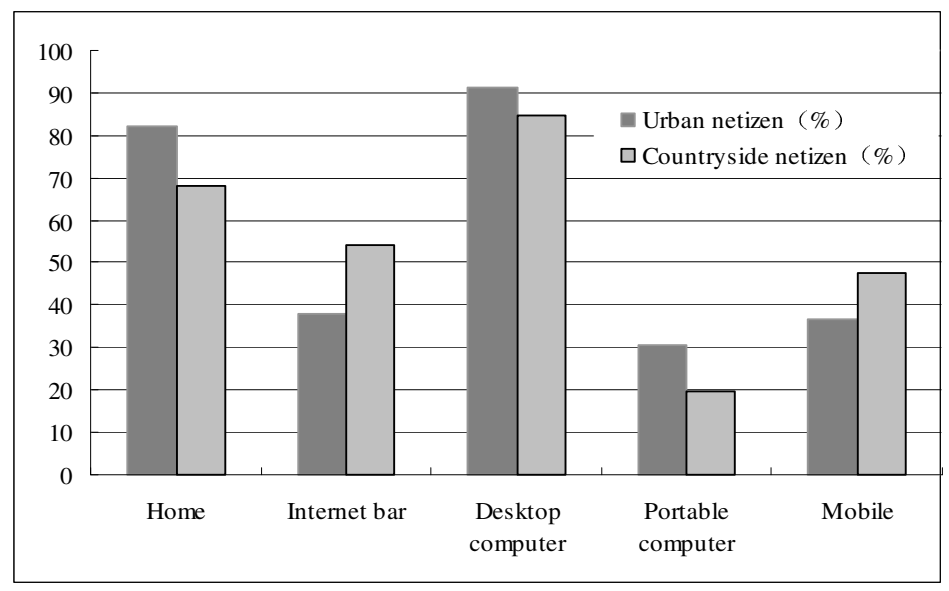

Fig. 1. Internet access method difference of netizen in Chinese urban and rural areas

\subsection{Netizen's School Record and Occupation in Urban and Rural Areas}

The netizen's difference in school record and occupation distribution between cities and the rural areas is quite obvious. In school record, the cultural level of rural areas netizen is relatively low, the netizen's school record in the junior middle school accounts for $42.3 \%$, is $20 \%$ higher than the cities; The rural areas netizen's proportion in high school is $38.6 \%$, which is $1.2 \%$ lower than that of the cities. The netizen's proportion in or above the technical college is $12.0 \%$, which is lower $33.2 \%$ far than the cities.In addition, the proportion in the elementary school and following cultural level accounts to be low in the netizen from urban and rural areas. From the contrast of netizen's occupational structure between rural areas and the cities, the students' number from the middle-school occupies $38.8 \%$, which is $7.6 \%$ higher than those from the cities' middle-schools; the jobless, people who have laid off, the unemployed and the farming and forestry herd fishing workers occupy a high rate in the countryside netizens.

\subsection{Netizen's Application Goal of Network in Urban and Rural Areas}

At present, the network application of the countryside netizens is unitary, which is mainly to entertain them selves. The attraction of internet to farmers mainly comes from the function of network leisure entertainment, network music, network video frequency, network game as well as network chats become the main purpose of using the internet to the rural areas netizen, its user scale has surpassed 50,000,000.The online listening and looking rate of network music, network film and television surpassed the cities, $86.4 \%$ and $76 \%$ of countryside netizens use these two functions of the network separately at the end of 2007.Many countryside netizens only regard internet as chating and amusement tool, in which the proportion of playing the network game has reached as high as $58.2 \%$. 


\subsection{Netizen's Network Demand and Understanding in Urban and Rural Areas}

The non-netizens want to connect the Internet in urban and rural areas and only $15 \%$ of people is not interested in it. Two reasons why the rural areas inhabitants don't often connect the internet are that they are lake of the skill and they don't have the relevant equipment. The investigation results at the end of 2007 (to see Figure 2) showed that the reason why $53.3 \%$ of non-netizen which is no surfing the internet of in the rural areas is lacking play skill on internet, compared to near $10 \%$ higher than cities non-netizens. The non-surfer equipment is one of the important reasons for rural areas inhabitant's surfer, its accounts for the proportion of $5.3 \%$ higher than the cities. In addition, the time for surfer has already leaped to the second tremendous influence factor which influenced the non-netizen to do no surfing instead of lacking the surfer equipment. In the investigation of rural areas non-netizens at the end of 2009, 38.8\% of no surfer people are lack of surfer skill, and $19.7 \%$ of no surfer people are short of surfer equipment as a result, only $3.5 \%$ of no surfer people does not have the condition.

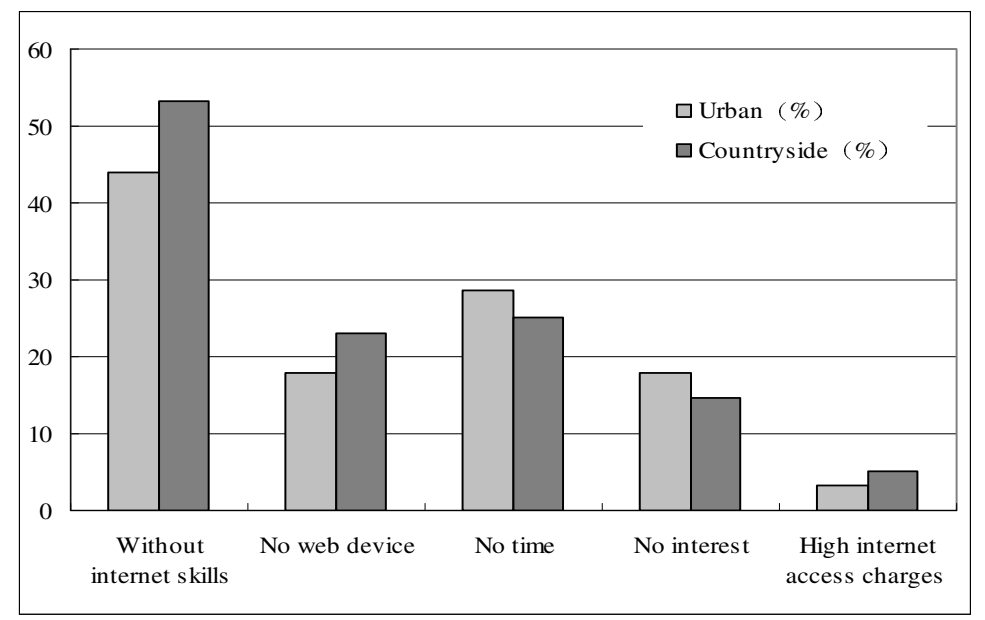

Fig. 2. Reason for not online of Chinese non-netizen by the end of 2007

\section{Analysis of "Internet Digital Divide" in Chinese Urban and Rural Areas}

\subsection{Construction of Rural Areas Informationization Infrastructure Has Begun to Take Shape}

The rural areas informationization construction has already became the important action of the socialism new rural reconstruction, in order to let the information technology and the service benefit trillion of farmers, the government has increased the support to the rural areas telecommunication and the internet. Up to the end of 2008, $98 \%$ of national villages and towns could access the net, $95 \%$ of villages and towns 
pass the wide band, and 27 provinces have realized "the township township to be able to access the net". In 2009, it realized "the village to village has telephoned, the township and township can access the net" in the area phone project basicly, the proportion of nation telephones of the administrative village and the natural village respectively achieved above $99.8 \%$ and $93 \%$, realized above $99 \%$ villages and towns to be able to access the net, $96 \%$ of villages and towns passed the wide band.

\subsection{Long-Standing of Internet Digital Divide in Urban and Rural Areas}

A lot of factors lead to the internet digital divide in urban and rural areas. Firstly, the superiority of the population scale and the density aspect in cities and towns, especially in cities, causes the scale income of the information infrastructure construction to be remarkable and they become the first choice. Secondly, the application demands from urban population to information infrastructure and so on in the internet are more intense, this has drawn the information infrastructure construction and the service supplies to a certain extent. Thirdly, the cities inhabitants have the high scientific cultural quality, and they have the superiority in the internet cognition and the surfer skill. Fourthly, the cities inhabitant's income is relatively high, this causes stronger bearing capaurban at aspects and so on in surfer equipment and fees. Fifthly, the urban inhabitants mainly do mental labor, while the rural areas inhabitants mainly do physical labor, the former is more convenient to connect the net .The above reasons which will exist for a long time have decided the long-term characteristic of internet digital divide question in urban and rural areas.

\subsection{Improving the Human Quality Is the Most Important Factorto Solve the Problem of Touching the Net for the Rural Areas Inhabitant}

The most important reason why the non-netizen in rural areas does not access the net is that they don't have the surfing skill. Currently speaking, the most essential factor with the surfer skill is inhabitant's scientific cultural quality. The height of scientific cultural quality often decide the height of a person with accepts ability to the new thing like internet cognition. Take the internet as the example, the junior middle school level was generally considered most elementary knowledge level which the surfer should have. This is because it should have writing recognition capability, as well as the information search, discernment and handling ability to use the internet skillfully, and it needs the cultural level of above the junior middle school at least. By contrast, the entertainment function is somewhat low to netizen's scientific cultural quality request. Therefore, to improve the rural areas inhabitant's scientific cultural quality becomes the most important question in solving the needs of rural areas netizen's touches to the net in China.

\subsection{Increasing the Farmer's Income Is the Key to Enhance the Rural Areas Internet Popularity Rate}

Personal economy payment ability is one of the factors that affects surfer or not, the reason of non-surfer equipment and expensive surfer expense which impact the nonnetizen doing not access the net all belong to this kind of situation. The appearance of "the internet digital divide" with regional characteristic in east, middle and west of 
China is caused by the local economy development difference. At the same time, the cities inhabitant's disposable personal income to maintain basically in 3 times (to see Figure 3) at the rural areas inhabitant's in recent five year, on the other hand the surfer fees invested are almost the same in purchasing surfer equipment in the urban and rural areas actually. Although the policy of "the electrical appliances went to the country" and so on to the rural areas inhabitant provide the convenient way for purchasing the computer, but affect limitedly in impelling to use computer to the rural areas area. Speaking of the majority of farmers, the computer is the luxurious thing. Along with the maturity of information and communication technology gradually as well as the widespread of application and range of service day by day, the dropping of "the economical threshold" in surfer is the inevitable trend. Therefore, to increase the farmer's income to enlarge the ratio of the average of per person net income/threshold of surfer economical unceasingly will be the key to enhance Internet popularizing rate in rural areas.

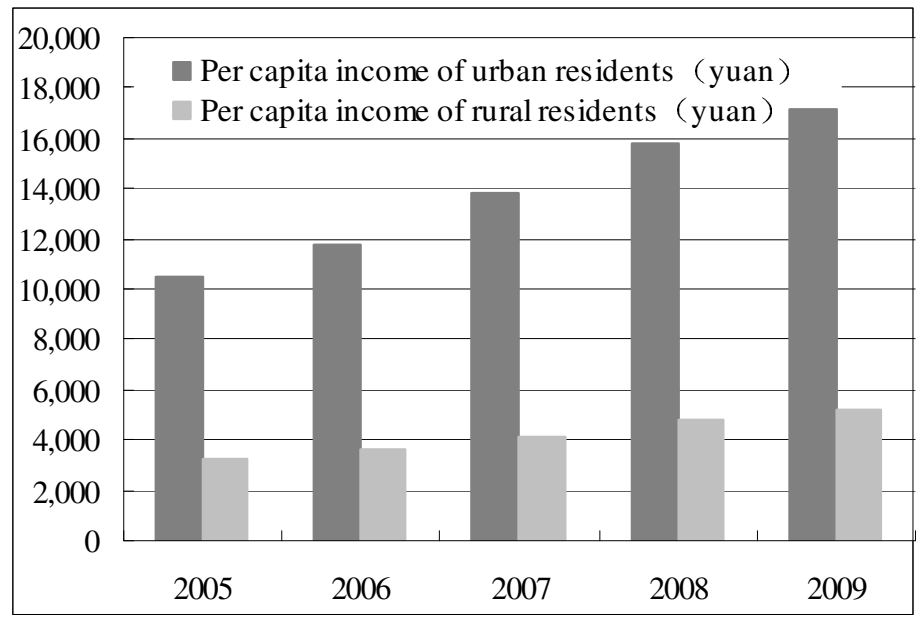

Fig. 3. China's per capita income from 2005 to 2009

\subsection{Mobilephone and Construction of Many Kinds of Information Service Center Is the Important Way for the Rural Areas People to Touch the Net}

At present, high economical threshold is still the important factor which restricts our country rural areas inhabitants to access the net, and this kind of condition cannot change too greatly in a short-term. The difference in the surfer place and way of netizen in the urban and rural areas shows that. Since the rural areas area cannot equally access the net in the way to the cities through purchasing individual computer and surfing on line at home to enhance the internet popularity rate, the mobile phone and construction of many kinds of information service centers become two big important ways in which the farmer touches the net. The economical threshold of surfing on line by mobile phone is lower a lot than through the computer, although the difference in function is great, but chooses the former in situation of not too realistic to choose the 
latter also to be acceptable. In addition, constructs including the internet bar, the internet information service station and so on which belongs to the different forms of concentric information service center, provides the basic hardware equipment, the farmer only need pay a little to access the net.

\section{Copying Strategy of Informationization Supply and Demand Docking in Chinese Rural Areas}

The informationization construction in Chinese rural areas, especially the solution of urban and rural areas, "internet digital divide" is a systematic work. It needs to start with both the supply and demand, namely "makes an offering needs", the concrete implication is to fully develop government's leading role in rural areas informationization supplies, mainly through construction of information infrastructure and policy guidance to realize information supplies; At the same time, it needs to enhance the farmer's information accomplishment through the multi-ways to increase information need in rural areas, thus help to realize the supply and demand docking of informationization construction in rural areas.

\subsection{Proceed to Develop Leading Roles in Rural Areas Informationization Supplies by Two Levels of Government}

In China, the achievement of rural areas informationization construction in national stratification plane is remarkable. Because the highly attention from national stratification plane, our country will realize the goal with $100 \%$ of administrative villages to telephone, $100 \%$ of villages and towns will be able to access the net in 2010.Here, the rural areas informationization in China, especially the network infrastructure construction has begun to take shape, the emphasis from now on is to realize the transformation from the infrastructure construction to the application and promotion and consummate service. The key actions included consummating the construction of rural areas information platform, sharpening the rural areas information service ability; fully propeling the activity of information to the country, perfecting rural areas information service system; using each item of agriculture-friendly policies, promoting the information terminal and the service to enter the village residence. In addition, the Central Party Committee, the State Council should continue to pay attention to informationization in rural areas, strengthen the cooperation and coordination of the Ministry of Agriculture, the Industry and the Informationization Department, and mobilize the subjective initiative of China Telecom, China Mobile and China Unicom as telecommunication enterprise, only then will safeguard the result of Chinese informationization construction and supplies in rural areas.

In various provincial levels administrative division, it should act according to the existing informationization construction foundation as well as the rural areas social economic condition, to choose the informationization construction measure in rural areas which suits its own. In different area of one province, it may choose the suitable way of rural areas informationization construction according to its own condition. South Korea implemented the construction plan of "the informationization demonstration village" which can provide the model for us. Through constructing the 
experiment site in the nation firstly, and it expanded and increased quantity way gradually to carry on after the success. Each of "the informationization demonstration villages" includes: (1) The internet infrastructure with high speed, and realizes the broadband networks to enter the peasant's household; (2)Establishing the village information center, disposes computer as hardware and so on and realizes connection to the local administration information network; (3) Constructing the network use environment of peasant's household, the existing demonstration village has achieved above $73 \%$ that peasant's household has provided the computer; (4)Establishes management operation system, forms the demonstration village operation committee of the villagers, and the informationization instructors and the information center administrative personnel participates in the operation together; (5)Carrying on the talented person to educate training and raising one batch of rural areas informationization backbone and the administrative personnel.

\subsection{Through Multi-ways in Enhancing the Farmer's Information Accomplishment to Increase the Information Need in Rural Areas}

Aims at the farmer to implement the informationization training popular project in rural areas, this project contains training and the propaganda \& popularity. The training object is the first-line managers in rural areas with village cadre, village staff, village information officer, the specialized farmer as well as the ordinary farmer has the enthusiastic. Training may be divided into two levels as the basic class and enhance class, and unifies to organize, develop and compile training materials according to the rural areas characteristic. The training spot should have the basic condition as below: Having some places with certain quantity of computer, condition of surfing online; Having the training teacher who is familiar to rural education characteristic. The object of propaganda and popularization is all villagers; The content is to introduce knowledge of computer, internet, mobile phone and so on to the rural areas inhabitant, to guide them to know about the internet and to raise information consciousness; The propaganda and popularization material may be compiled voluntarily by the urban or by the actual situation of various county unions; The form of propaganda and popularization is mainly "the small information boxcar" to enter the market town, village, shop and so on, organizing the rural areas inhabitant to watch the propaganda short film, to join the experience activity and to read popular reader.

Allocated the agricultural information officer to provide the surfer instruction for farmers, this paper has mentioned that construction of information service center with many kinds of form is one of important ways which the rural areas touches the net. At present, the information service center mainly manifests the form of agricultural information service station for the basic units as town, village and so on. But in the process of service station construction, we need to consider the flaw of rural areas inhabitant in surfer skill, therefore it must provide all levels of agricultural information officer and carry on the training to the farmer and provide the surfer instruction for them as necessary. At the same time, the agricultural information officer can also display the potency in the aspect of information supply, reorganize and issue the rural areas information through preparing for construction and manages local agricultural information network, and organize farmers to participate in it. 
To popularize the rural areas informationization popularization with the training by the university student village officials is a very important action. Apart from allocating the agricultural information officer to provide the surfer instruction for the farmer, but also another way may get up the effect of "fans out from point to area" in the rural areas, namely through the university student village officials as "spot" then leads its in the village as "surface". The university student village official has the high scientific cultural quality, the strongly information consciousness, moreover they have grasped the highly surfer skill in school period, simultaneously they have the work superiority in village, therefore it only needs to make part of the development training pointedly, they may play the role which cannot be substituted in training farmer's information consciousness, the promotion and use of rural areas informationization work and so on in a series of key links. The result is that each university student village official leads the informationization construction of a village, the general university student village official can lead the entire informationization level in local rural areas naturally.

This paper also mentioned that it was necessary to understand student's vital role in rural areas informationization correctly. At present, the middle-school student community occupies as high as $38.8 \%$ of the netizens in Chinese rural areas. The student is the main body of farmer informationization, simultaneously it is also the latent strength which will decide the future level of rural areas informationization. Therefore, we should correctly understand student's vital role in rural areas informationization.It needs to enlarge the promotion work of internet popularization in the rural areas school for enhancing the rural areas student's informationization accomplishment. The school must take the internet education as an important content of daily teaching, to guarantee students to have the basic surfing skill after the graduation from middle school, thus promoting enhancement of rural areas informationization level with steady steps. In this process, the school must also let students realize the positive aspects of the internet and restrain the negative ones through education.

\section{Conclusion}

The internet construction in rural areas area must be based on the correct cognition of "the internet digital divide" in the urban and rural areas, this includes both level of development disparity in social economy between the provinces even in different areas of the same province, and it also includes long-term and the alleviation difficulty which this question exists. Therefore, we put forward that improving the human quality is the most important factor for the rural areas inhabitants to touch the net, increasing the farmer income is the key to enhance the internet popularity rate in rural areas, the mobile phone and information service center construction with many kinds of forms is the important way which the rural areas touches the net. The information network construction in Chinese rural areas has already began to take shape in the period of "The Eleventh Five-Year Plan", the present key question has shifted to the questions of the lag of application conformity and the unsure grasp to farmer's true demand and so on. This needs us to obtain from two aspects as the supply and 
demand, we should display the leading role of government in rural areas informationization supplies, simultaneously enhance the farmer's information accomplishment in multi-ways to increase the information need in rural areas, and thus helping to realize the supply and demand docking of rural areas informationization construction.

\section{Reference}

1. Li, D.: China Rural Informatization Development Report 2009. Publishing House of Electronics Industry, Beijing (2009) 